\title{
Grand challenges for translational materials science
}

\author{
Oliver Hayden* \\ Corporate Technology, Siemens AG, Erlangen, Germany \\ ${ }^{*}$ Correspondence: oliver.hayden@siemens.com \\ Edited and reviewed by: \\ Jon Ajuria, IK4-Ikerlan, Spain
}

Keywords: materials science, engineering, healthcare, industry, energy, innovation, translational research, prototypes

Materials are undoubtedly the hidden champions of healthcare, biotechnology, or energy innovations, nevertheless, novel materials are not automatically translated into products. The success of functional materials is not a matter of luck; it is the result of years of failure and the painstaking design of the fundamental translational steps from materials science to real-world prototypes.

\section{CONNECT SCIENTISTS AND ENGINEERS FOR MATERIALS INNOVATION}

The need for a tight collaboration in the discovery-to-product translation process between scientists and engineers is often underestimated. The genius of these two communities is equally important; not only for the integration of novel materials into functional devices but also for the adaptation to the ever changing constraints of the market. Translational Materials Science reacts to the need of filling the communication gap among different players of the translation process and provides an optimal platform of sharing the information related to the efforts connecting basic science to product launch.

Market needs and materials applications evolve in parallel and continuously affect each other, just as in the case of the crackresistant glass for smart phones or the photoresist for lithography for true nanoscale CMOS field-effect transistors.

Furthermore, materials innovation requires public-private partnership instead of the current practice of small teams and black box thinking due to the necessity for high and long-term investments.

A beautiful example on how translation occurs is the hype on bottomup synthesized semiconducting nanowires that triggers CMOS top-down nanowire engineering work to rescue Moore's law with novel device architectures and hybrid semiconductors of group IV and III-V semiconductors for higher charge carrier mobilities. In the fields of biotechnology, in vitro diagnostics and therapy the facile synthesis of magnetic nanoparticles with biological coatings. This innovation changed fundamentally our understanding of how to benefit from magnetism to separate, enrich, and label biological specimen without the need for invasive or cumbersome methods. For instance today, we can use magnetic nanoparticles to enrich specimen for in vitro diagnostics without the need for centrifugation steps, which enables highly automated pre-analytical workflows. The last example is related to efficient energy storage, which is fundamental for our mobile world. Only the high energy storage capacity and the exquisite recharging properties of lithium-ion batteries enabled today's mobile communication world, which would have otherwise restricted our mobility to the length of a power cord.

\section{REPORT BOTH BREAKTHROUGHS AND FAILURES}

Besides the technical hurdles that we face during the implementation of materials, our main challenge remains the current bias in the publishing habits of the community. While we all understand that research failure is highly important for a material innovation, the community has been partial in reporting only success in line with the practices in academia. The pressure for publication and - as a consequence - traditional reviewing policies led to a situation that we neglect most of our research efforts although this usually is the most interesting learning experience we have. Translational Materials Science was born with the aim to demonstrate that properly documented failures are just as valuable as positive results.

\section{BEYOND NOVEL MATERIALS: UPSCALING AND RETARGETING ARE FUNDAMENTAL TO MATERIALS APPLICATIONS}

Translational material breakthroughs are not limited to the discovery of novel materials but can also be the result of cleverly upscaled processes or a well-designed retargeting.

The materials innovation process is a reverse analogy of David and Goliath: impact size does matter in the final product outcome. The past few years witness how novel organic solar cells innovations were overwhelmed by the market force of cost reduced fabrication of silicon solar cells. "Goliath" silicon solar cells prevail in photovoltaic power stations since they integrate scalable interface engineering technologies such as atomic layer deposition with high deposition rates. Still, recent efficiency improvement at low cost open new horizons for the "David" organic photovoltaic or perovskite technology in alternative market niches.

\section{OPEN-ACCESS CULTURE, A BENEFIT FOR THE PUBLIC, INDUSTRY, AND ACADEMIA}

One form of communication gap is traditionally imposed by the paywall of subscription-based academic journals that exclude readers with no institutional packages that are only affordable over a critical company size. Companies tend to focus on highly defined research goals, thus are typically not motivated to invest significant sums of money to cross this paywall before it is even verified that the content could be useful for reaching their targets. This not only causes companies to fail to read about academic achievements but also breaks the loop of communication. Smaller companies do not have access to the most up-todate knowledge base of academia but are also not incentivized to contributing to it, 
which is in turn a big loss of know-how for both parties.

The importance of the alignment to processes, e.g., safety, workplace regulations, end-customer requirements could be efficiently conveyed to materials scientists through publications whose creative thinking is typically not focusing on these.

Besides the major differences in career driving forces in the two worlds, we also acknowledge that intellectual property issues may be a major obstacle. For this reason, we are also fully open to the publication of white paper articles that would not cause any conflict related to patents.

\section{THE PEER REVIEW AS A SOURCE OF NEW COLLABORATIONS}

The editorial board of Translational Materials Science is constructed in a way that both academia and industry are equally represented.
We rely on the Frontiers peer review system because this enables fast, transparent, and a completely collaborative evaluation of articles. Our Editors' role is not merely to point out the weak parts of a manuscript, but also to contribute to it and make it better through a direct interaction with the authors on the Review Forum.

Lively discussions between authors, readers, and reviewers are to be expected and highly encouraged in the Frontiers blogs.

We are confident that this publishing model, Open-Access, and constructive, ensures the best way to promote the necessary collaboration for a successful materials innovation and translation process.

FINAL REMARK AND DISCLAIMER

The Translational Material Science community of authors and editors seeks to learn what provides the perfect environment for new materials and their first real-life steps.
We wish to enrich the public knowledge by ensuring an Open-Access insight for the reader to the myriad influencing factors that turn materials into future innovation.

Conflict of Interest Statement: The author declares that the research was conducted in the absence of any commercial or financial relationships that could be construed as a potential conflict of interest.

Received: 18 May 2014; accepted: 13 June 2014; published online: 30 June 2014.

Citation: Hayden $O$ (2014) Grand challenges for translational materials science. Front. Mater. 1:5. doi: 10.3389/fmats.2014.00005

This article was submitted to Translational Materials Science, a section of the journal Frontiers in Materials. Copyright (c) 2014 Hayden. This is an open-access article distributed under the terms of the Creative Commons Attribution License (CC BY). The use, distribution or reproduction in other forums is permitted, provided the original author(s) or licensor are credited and that the original publication in this journal is cited, in accordance with accepted academic practice. No use, distribution or reproduction is permitted which does not comply with these terms. 